\title{
A Synchronous undifferentiated nasopharyngeal carcinoma and infiltrating ductal carcinoma of the breast successfully treated with induction chemotherapy followed by local control of both tumours: a case report
}

Mohamed Mesmoudi ${ }^{*}$, Tarik Mahfoud ${ }^{1}$, Nabil Ismaili ${ }^{1}$, Khadija Rami $^{2}$, Meryem Kamouni $^{3}$, Laila Jroundi ${ }^{4}$ and Hassan Errihani ${ }^{1}$

\begin{abstract}
Background: Multiple primary cancers have a low incidence particularly when cancers are synchronous. Few cases of synchronous head and neck cancer and breast carcinoma are reported in the literature.

Case presentation: We report here an exceptional case of a 47 years old Moroccan woman presenting two synchronous cancers, the first in the nasopharynx and the second in the breast. The patient was treated successfully with a combined strategy associating chemotherapy, radiation therapy, and surgery. She remains disease free after 27 months of follow up.
\end{abstract}

Conclusions: Treatment strategy in the case of multiple primary cancers remains controversial because of the variety of presentations; initial aggressive treatment reports good results.

\section{Background}

The incidence of multiple primary cancers (MPC) is estimated between $0,73 \%$ and $11,7 \%$ [1]. The association of different cancers is classified in two categories depending on the timing of their discovery; synchronous in which the cancers occur at the same time or within two months, as the case that we report, or metachronous in which the cancers follow in sequence of more than two months apart [2].

The undifferentiated carcinoma of the nasopharynx is a common cancer in North Africa and in the Mediterranean basin, but the incidence of a double malignancy including a nasopharyngeal carcinoma is very uncommon. We report here a case of an undifferentiated nasopharyngeal carcinoma with a synchronous breast cancer

\footnotetext{
* Correspondence: mohamedmesmoudi@yahoo.fr

'Department of Medical Oncology, National Institute of Oncology, Rabat, Morocco
}

Full list of author information is available at the end of the article treated successfully with induction chemotherapy followed by local control of both tumours.

\section{Case presentation}

A 47 years old Moroccan woman with a familial history of a father dead from a colorectal cancer, and a maternal aunt dead from a breast cancer, presented to our institute with complaints of nasal obstruction, headache, and ear fullness for three months, and skin changes on the right breast for two months. She did not breastfeed her four children, had a regular menstrual cycle, and took oral contraception.

On physical examination, the right breast had a $6 \times 5 \mathrm{~cm}$ lump on retroareolar area fixed to the skin with thickening of the whole breast and nipple retraction. The axillae and the cervical regions were free of any adenopathy. Mammogram showed an increase in density on the right breast with abnormal skin thickening in the periareolar area and associated microcalcifications (Figure 1), the complement of ultrasound revealed a nodular lesion 


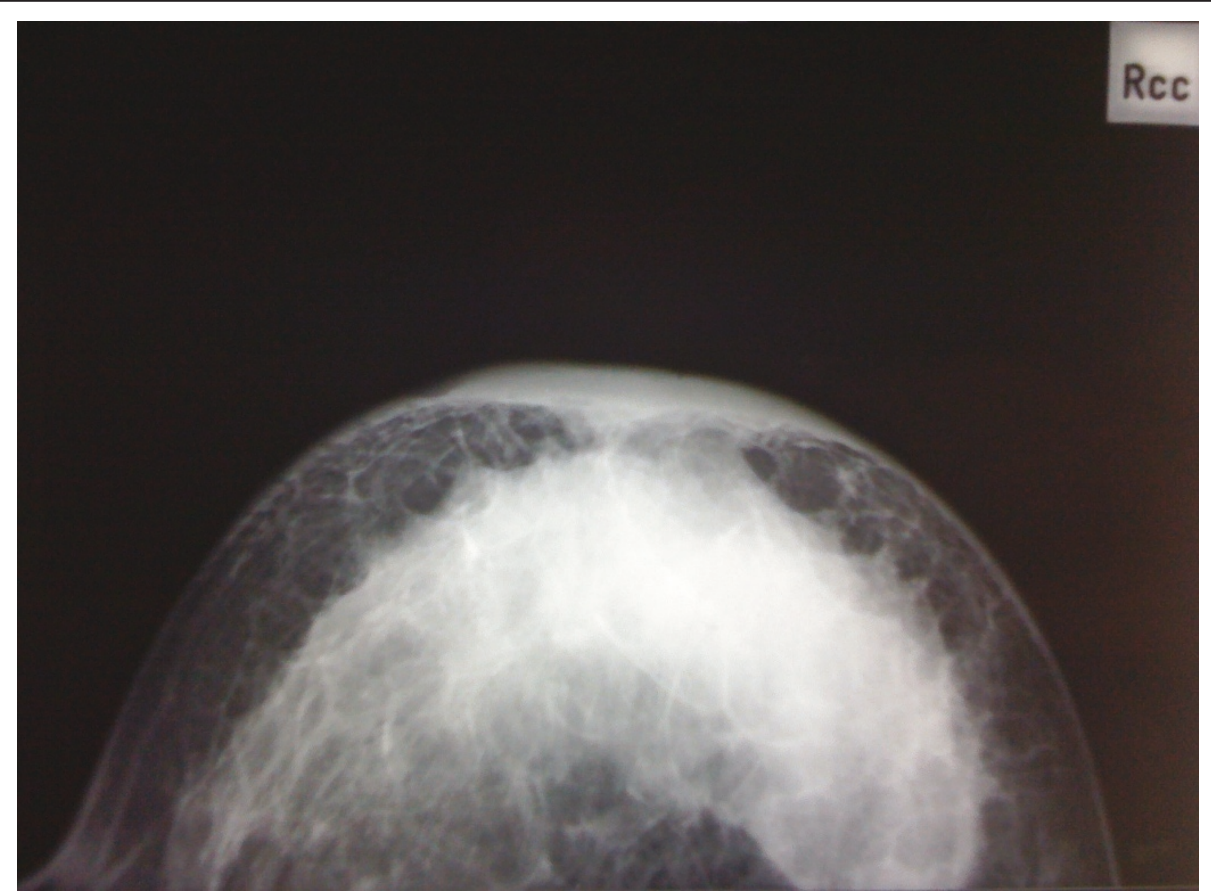

Figure 1 Breast mammogram. Right breast mammogram showing an increase in density on the right breast with abnormal skin thickening in the periareolar area and associated microcalcifications.

measuring $4 \times 4 \mathrm{~cm}$. On the fine needle aspiration cytology there were signs of malignancy confirmed with core biopsy of the lump suggesting a ductal infiltrating carcinoma with micropapillary component (Figure 2).

At presentation our patient had developed a unilateral conductive hearing loss associated with recurrent otitis media and numbness of the face. A computed tomography (CT) of the face and the skull showed an asymmetric mass in the posterior nasopharynx extended into the adjacent parapharyngeal spaces and infiltrating the sphenoid bone, no regional adenopathies were revealed, and the nasopharyngeal biopsy confirmed the diagnosis of an undifferentiated nasopharyngeal carcinoma (Figure 3). There were no distant metastases and we conclude the diagnosis of a locally advanced breast cancer with a synchronous stage III undifferentiated nasopharyngeal carcinoma.

The patient received induction chemotherapy combination of drugs sharing an activity on breast and nasopharyngeal carcinomas, association of taxanes and anthracyclines drugs was used (weekly Paclitaxel $80 \mathrm{mg} /$ $\mathrm{m}^{2}$ for 12 weeks associated to Doxorubicine $50 \mathrm{mg} / \mathrm{m}^{2}$ every 3 weeks) for a total of 4 cycles. The treatment was generally well tolerated; the patient had 3 episodes of grade III-IV non febrile neutropenia, grade II mucositis, total alopecia, and grade II neuropathy reversible after several months thereafter. After the four cycles of chemotherapy there were a remarkable improvement on the breast and a relief in the symptoms of the nasopharyngeal tumour.

The induction therapy was followed by external beam radiation for the nasopharynx (70Gy in 35 fractions) with concurrent chemotherapy (weekly Cisplatine 40 $\mathrm{mg} / \mathrm{m} 2$ for four weeks) and a prophylactic radiation to cervical lymph nodes. Evolution was marked by the improvement of the symptoms and a radiological reduction volume of the nasopharyngeal mucosa thickening which biopsy confirmed the absence of malignancy. This sequelar lesion has persisted until the last control without trend to progression.

Breast intervention was delayed until after the local control of the nasopharyngeal tumour. A right-sided modified radical mastectomy with axillary nodes dissection was carried out. Histological analysis of the mastectomy specimen revealed a $2 \mathrm{~mm}$ residual infiltrating ductal carcinoma grade II, neither insitu component nor lymphovascular emboli were found, hormonal receptors were positives $(90 \%$ on estrogens receptor, and $30 \%$ on progesterone receptor), Her2 status was negative, and from the 11 lymph nodes dissected 4 were involved. Surgery was followed by chest wall irradiation, and the patient undergoes now an antihormonal therapy; she has accomplished 12 months of Tamoxifene. The latest medical controls show no signs of locoregional relapse for both tumours and our patient remains disease-free 27 months after beginning therapy. 


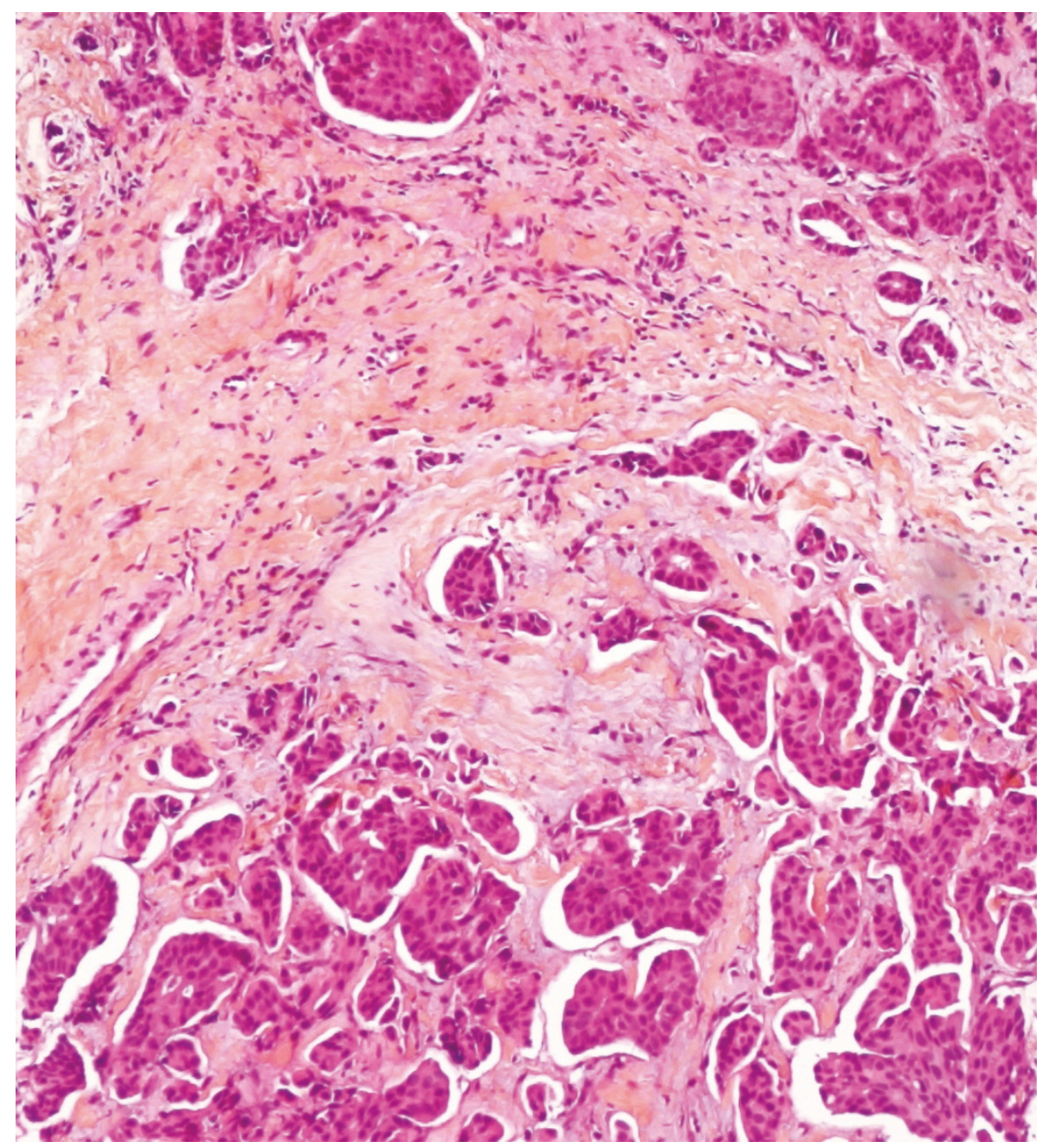

Figure 2 Histopathology of the breast lesion. Photomicrograph of the histopathological analysis of the breast biopsy showing an infiltrating ductal carcinoma grade II.

\section{Conclusions}

The presence of multiple synchronous tumours in the head and neck area and the upper aerodgestive tract is well established $[3,4]$, this association has been explained by the concept of "field cancerization"[5]. In a Chinese analysis $3 \%$ of patient with nasopharyngeal carcinoma develop a second cancer, most common site are the aerodigestive tract, lymphoproliferative malignancies, skin, and connective tissue. The risk of developing a second breast cancer was estimated to 1,34 [6].

Sel'chuk et al in 100 patients with head and neck cancers found a rate of $19 \%$ of synchronous tumours detected on the breast [7]. Strobel et al in a systematic detection of synchronous primaries to squamous head and neck carcinomas on 589 patients found one case of breast second cancer [8]. Driss et al have reported a case of breast metastases from an undifferentiated nasopharyngeal carcinoma, in the English literature there is only three well documented cases of this setting [9]. The association that we report here includes two primary sites from different histological types.

A retrospective study by Di Martino et al concerning the survival in second primary malignancies of patients with head and neck cancers conclude that the prognosis of synchronous tumours is significantly lower when compared to malignancies of a metachronous nature, results report $26 \%$ of 5 year overall survival for metachronous setting after the occurrence of the second cancer, and $11,9 \%$ for the synchronous setting ( $\mathrm{p}<0,0001$ ), a second interesting conclusion from this study is that only the early implementation of aggressive treatment methods for second primaries is successful in terms of survival [10]. In our case we have opted for this aggressive strategy and treated our patient with combined 


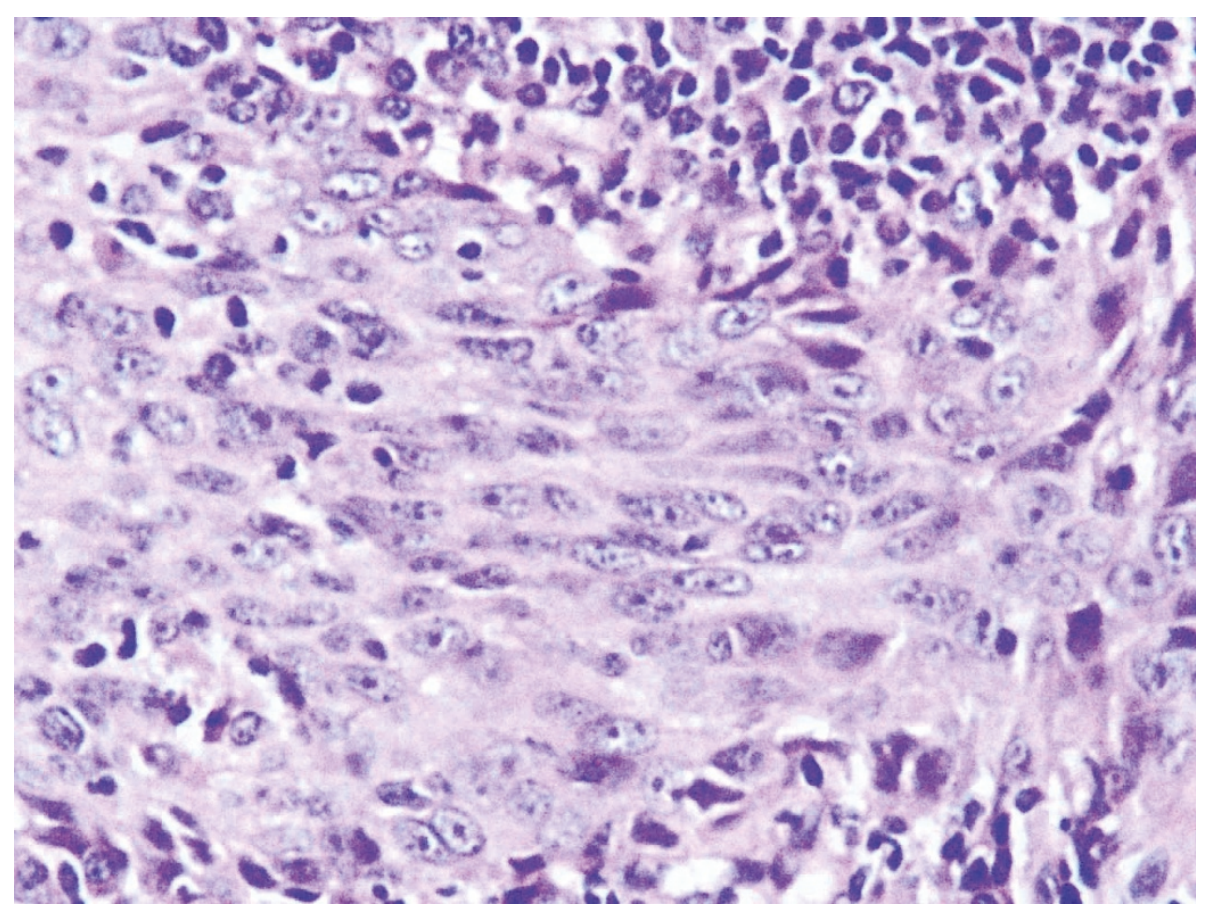

Figure 3 Histopathology of the nasopharyngeal lesion. Photomicrograph of the histopathological analysis of the nasopharynx biopsy showing the aspect of an undifferentiated carcinoma.

modality of chemotherapy drugs which have an activity on the breast and nasopharyngeal cancers followed by local control therapy of both tumours. Results were encouraging with a survival exceeding two years and without local or distant relapse.

The distinctive racial/ethnic and geographic distribution of NPC worldwide suggests that both environmental factors and genetic traits contribute to its development, well-established risk factors for NPC include elevated antibody titers against the Epstein-Barr virus (EBV), consumption of salt-preserved fish, a family history of NPC, and certain human leukocyte antigen class I genotypes [11]. In another hand, an association between two primaries suggests common ethological risk factors.

Positive association between alcohol intake and carcinoma of the breast has been consistently demonstrated [12]. In the case of the nasopharyngeal carcinoma a systematic review by Chen et al suggests that heavy alcohol consumption is associated with an increased risk of NPC [13]. Our patient had no history of alcohol intake.

Besides of the exogenous risk factors, Bongers et al suggest that an intrinsic susceptibility may influence the risk for the development of second primary tumours in patients with head and neck carcinoma [14], the familial history of cancer in the case that we report might invoke the genetic susceptibility in the pathogenesis of this association of primaries and the hereditary predisposition to multiple cancers.
Other explanation could be the role of EBV which implication is well established like etiological factor of NPC, furthermore, a recent study by Mazouni et al provides evidence for EBV-associated breast cancer undergoing distinct carcinogenic processes with more aggressive features [15]. At last, this unusual association of breast cancer and NPC would be due to a chance phenomenon.

Synchronous double malignancy of head and neck and breast is very uncommon, etiology remains obscure, there is no standard approach for the treatment strategy, and in our case treating both malignancies with the same induction chemotherapy combination followed by local therapy was successful.

\section{Consent}

Written informed consent was obtained from the patient for publication of this case report and accompanying images. A copy of the written consent is available for review by the Editor-in-Chief of this journal.

\section{List of abbreviations}

CT: Computed tomography; EBV: Epstein Barr virus; MPC: Multiple primary cancer; NPC: Nasopharyngeal carcinoma.

\section{Author details}

${ }^{1}$ Department of Medical Oncology, National Institute of Oncology, Rabat, Morocco. ${ }^{2}$ Department of Radiation Therapy, National Institute of Oncology, Rabat, Morocco. ${ }^{3}$ Department of Histopathology, National Institute of Oncology, Rabat, Morocco. ${ }^{4}$ Department of Radiology, National Institute of Oncology, Rabat, Morocco. 


\section{Authors' contributions}

MM was involved in the analysis of the data, the literature research and wrote the manuscript, $\Pi T$ helped write the manuscript and the literature research, NI helped with modifications and revision of the manuscript, KR approved the radiotherapy part of our patient, MK approved the histopathological part of the case, $\sqcup$ approved the radiological part of the case, HE managed the patient, approved the treatment and analyzed the literature data. All authors read and approved the final manuscript.

\section{Competing interests}

The authors declare that they have no competing interests.

Received: 4 February 2011 Accepted: 9 June 2011

Published: 9 June 2011

\section{References}

1. Demandante CG, Troyer DA, Miles TP: Multiple primary malignant neoplasms: case report and a comprehensive review of the literature. Am J Clin Oncol 2003, 26(1):79-83.

2. A review of the definition for multiple primary cancers in the United States. In Workshop Proceedings from December 4-6, 2002, in Princeton North American Association of Central Cancer Registries: New Jersey, Springfield (IL) Edited by: Howe HL 2003.

3. Rennemo E, Zätterström U, Boysen M: Synchronous second primary tumors in 2,016 head and neck cancer patients: Role of symptomdirected panendoscopy. Laryngoscope 2011, 121(2):304-309.

4. Hujala K, Sipilä J, Grenman R: Panendoscopy and synchronous second primary tumors in head and neck cancer patients. Eur Arch Otorhinolaryngol 2005, 262(1):17-20, Epub 2004 Mar 5.

5. Slaughter DP, Southwick HW, Smejkal W: Field cancerization in oral stratified squamous epithelium: clinical implications of multicentric origin. Cancer 1953, 6:963-968.

6. Chen M-C, Feng I-J, Lu C-H, Chen C-C, Lin J-T, Huang S-H, Lee K-D: The incidence and risk of second primary cancers in patients with nasopharyngeal carcinoma: a population-based study in Taiwan over a 25-year period (1979-2003). Annals of Oncology 2008, 19:1180-1186.

7. Sel'chuk VI, Temnikov Al, Popova TN: Specifics of diagnosis in primarymultiple synchronous tumors of the head and neck. Vopr Onkol 2001, 47(1):90-2.

8. Strobel K, Haerle SK, Stoeckli SJ, Schrank M, Soyka JD, Veit-Haibach P, Hany TF: Head and neck squamous cell carcinoma (HNSCC)-detection of synchronous primaries with (18)F-FDG-PET/CT. Eur J NuCl Med Mol Imaging 2009, 36(6):919-27.

9. Driss M, Abid L, Mrad K, Dhouib R, Charfi L, Bouzaein A, Ben Romdhane K: Breast metastases from undifferentiated nasopharyngeal carcinoma. Pathologica 2007, 99(6):428-30.

10. Di Martino E, Sellhaus B, Hausmann R, Minkenberg R, Lohmann M, Esthofen MW: Survival in second primary malignancies of patients with head and neck cancer. JLaryngol Otol 2002, 116(10):831-8.

11. Chang ET, Adami HO: The enigmatic epidemiology of nasopharyngeal carcinoma. Cancer Epidemiol Biomarkers Prev 2006, 15(10):1765-77.

12. Brennan SF, Cantwell MM, Cardwell CR, Velentzis LS, Woodside JV: Dietary patterns and breast cancer risk: a systematic review and meta-analysis. Am J Clin Nutr 2010, 91(5):1294-302.

13. Chen L, Gallicchio L, Boyd-Lindsley K, Tao XG, Robinson KA, Lam TK, Herman JG, Caulfield LE, Guallar E, Alberg AJ: Alcohol consumption and the risk of nasopharyngeal carcinoma: a systematic review. Nutr Cancer 2009, 61(1):1-15.

14. Bongers $V$, Braakhuis BJ, Tobi H, Lubsen H, Snow GB: The relation between cancer incidence among relatives and the occurrence of multiple primary carcinomas following head and neck cancer. Cancer Epidemiol Biomarkers Prev 1996, 5:595-8.

15. Mazouni C, Fina F, Romain S, Ouafik L, Bonnier P, Brandone JM, Martin PM: Epstein-Barr virus as a marker of biological aggressiveness in breast cancer. Br J Cancer 2011, 104(2):332-7.

\section{Pre-publication history}

The pre-publication history for this paper can be accessed here:

http://www.biomedcentral.com/1472-6815/11/6/prepub doi:10.1186/1472-6815-11-6

Cite this article as: Mesmoudi et al:: A Synchronous undifferentiated nasopharyngeal carcinoma and infiltrating ductal carcinoma of the breast successfully treated with induction chemotherapy followed by local control of both tumours: a case report. BMC Ear, Nose and Throat Disorders 2011 11:6.

\section{Submit your next manuscript to BioMed Central and take full advantage of:}

- Convenient online submission

- Thorough peer review

- No space constraints or color figure charges

- Immediate publication on acceptance

- Inclusion in PubMed, CAS, Scopus and Google Scholar

- Research which is freely available for redistribution

Submit your manuscript at www.biomedcentral.com/submit
Biomed Central 